\title{
MANAJEMEN PENGELOLAAN TOILET UMUM DI DAYA TARIK WISATA KUTA
} LOMBOK TENGAH

\author{
Oleh \\ Ni Luh Sueni Widyanti'), Maya Aulia Anggreni'2), I Nengah Juni Sumardiana3), \\ Hendri Yasti $\left.{ }^{4}\right)$ \& Rizal Kurniansah ${ }^{5)}$ \\ 1,2,3,4,5Sekolah Tinggi Pariwisata Mataram \\ Email: 1niluhsueniwidyanti7643@gmail.com, ${ }^{2}$ mayaa7276@gmail.com, \\ 3 junisumardianastp@gmail.com \& ${ }^{4}$ rizalkurniansah@gmail.com
}

\begin{abstract}
In Kuta Lombok tourist destination, adequate supporting facilities are needed, one of which is public toilets, public toilets which are an important part of the needs of tourists, for that we need good maintenance needs to provide a sense of comfort for tourists. The purpose is to find out the management of public toilets in the tourist attraction of central Lombok Lombok and the management of public toilet management. Data collection methods are interviews, observation and documentation. The results of research conducted on public toilets in the tourist attraction of Kuta Lombok are still not running optimally. This is evident that there are still toilets that do not meet hygiene and sanitation standards. In its management there needs to be a close collaboration between the government and the community so that the management of public toilets goes well. Based on the results of this study it can be concluded that the management of public toilets in the tourist attraction of Kuta Lombok is not going well.
\end{abstract}

Keywords: Management, Toilets, Kuta \& Lombok

\section{PENDAHULUAN}

Pulau lombok merupakan sebuah pulau memiliki banyak potensi wisata di Indonesia, ada berbagai jenis potensi wisata yang terdapat di pulau lombok antara lain wisata alam, seni dan budaya, wisata syariah (Rozita dkk, 2019) dan wisata perkotaan (Kurniansah dan Rosida, 2019). Kementerian Pariwisata Indonesia tengah mencanankan Lombok sebagai daerah super prioritas untuk dikembangkan sebagai destinasi pariwisata di Indonesia dinama salah satu destinasi pariwisata di pulau Lombok yaitu Kuta menjadi ikon utama untuk dijadikan sebagai destinasi pariwisata utama. Sebagai bentuk keseriusan pemerintah untuk mengambangkan pariwisata Kuta Mandalika Lombok, saat ini telah ada hotel-hotel berbitang yang ada di Kuta seperti Novotel dan Pullman dan bahkan pada tahun 2021, di Mandalikan Lombok akan diselenggarakan event berskala Internasional yaitu MotoGP, (Kompas, 2019). Perkembangan tersebut menjadi berkah tersendiri bagi Pulau Lombok, karena berkembangnya pariwisata tentu akan menggerakkan perekonomian masyarakat setempat.

Untuk mengembangkan suatu destinasi pariwisata maka di perlukan juga keberadaan komponen pendukung pariwisata salah satunya adalah fasilitas umum, (Kurniansah dan Hali, 2018). Keberadaan fasilitas ini sangat penting untuk kebutuhan para wisatawan seperti restoran, hotel, mushola maupun fasilitas publik lainya yaitu toilet umum. Toilet umum merupakan fasilitas publik yang wajib tersedia di suatu destinasi pariwisata Kuta Lombok. Mengingat 
pentingnya keberadaan toilet umum ini maka perlu dikembangkan dan dikelola dengan baik.

Eksistensi toilet merupakan bagian penting kebutuhan manusia untuk tidak hanya sekadar buang hajat. Fasilitas umum ini harus dikelola dengan sebaik- baiknya dengan memperhatikan beberapa aspek yang bisa menyelamatkan, menyehatkan, mengamankan, menyamankan, memudahkan, dan menyamankan baik pengguna maupun pengelola, (Darwis, Hendranigrum, dan Adriani, 2016).

Sebagai destinasi pariwisata prioritas di Pulau Lombok, Kuta perlu mempersiapkan dirinya untuk menjadi tujuan wisata yang menarik untuk dikunjungi. Keberadaan toilet umum harus tersedia, hanya saja berdasarkan hasil observasi yang dilakukan masih terdapat toilet umum di Kuta Lombok yang belum dikelola dengan baik, bahkan terkesan diabaikan dan rusak. Adanya fenomena tersebut tentu dibutuhkan sinergitas antara masyarakat dan pemerintah agar mengelola toilet umum dengan baik, sehingga kedepannya dapat menimbulkan citra yang baik tentang Kuta Lombok serta memberikan rasa nyaman bagi wisatawan yang berkunjung.

Berdasarkan latar belakang diatas, tim penulis merumuskan permasalah sebagai berikut yaitu bagaimanakan pengelolaan toilet umum di daya tarik wisata Kuta Lombok, serta bagaimanakan manajemen pengelolaan tolet umum di Kuta Lombok. Tujuan dari penelitian ini yaitu untuk mengetahui serta memberikan masukan kepada masyarakat dan pemerintah dalam mengelola toilet umum di Kuta Lombok. Melalui penelitian ini juga diharapakan memberikan manfaat kepada pengelola toilet umum agar mengelola toilet dengan baik serta mampu memberikan rasa nyaman bagi para wisatawan. sehingga kedepannya destinasi pariwisata Kuta Lombok menjadi tujuan wisata favorit di Indonesia.

Tujuan dari Artikel Ilmiah ini yaitu (1) Untuk mengetahui pengelolaan toilet umum di daya tarik wisata kuta lombok. Mendeskripsikan manajemen pengelolaan toilet umum di daya tarik wisata Kuta Lombok.

\section{METODE PENELITIAN}

\section{a. Observasi, Lokasi Penelitian dan Waktu Pelaksanaan}

Secara umum cara observasi yang dilakukan dalam penelitian ini yaitu terjun langsung di lokasi penelitian dengan mengamati lansung, serta melakukan beberapa wawancara kepada stakeholders di lokasi penelitian. Penelitian ini dilaksanakan di Desa Kuta Kabupaten Lombok Tengah Provinsi Nusa Tenggara Barat. Alasan mengambil lokasi tersebut yaitu kuta sebagai salah satu daya tarik wisata Lombok semakin berkembang seiring dengan diresmikannya Kawasan Ekonomi Khusus (KEK) Mandalika menjadi alasan tersendiri apakah kawasan tersebut telah benar-benar siap untuk melaksanakan kagitan pariwisata. Waktu pelaksanaan dilaksanakan lebih kurang selama 1 bulan, terhitung mulai 5 September 2019 sampai dengan 5 Oktober 2019.

\section{b. Metode Pengumpulan Data}

- Wawancara yaitu teknik pengumpulan data dengan cara melakukan tanya-jawab langsung antara peneliti dengan informan secara mendalam tentang topik yang diangkat dalam penelitian. Informaninforman tersebut antara lain Kapala Dinas Pariwisata, Masyarakat dan Pelaku Usaha Wisata di kabupaten Lombok Tengah.

- Metode Observasi yaitu teknik pengumpulan data yang dilakukan 
dengan cara mengamati dan mencatat setiap gejala atau fenomena yang diteliti di lokasi penelitian. Observasi yang akan dilakukan oleh peneliti yaitu mengamati kondisi terkini terhadap pengelolaan toilet.

- Metode Dokumentasi Dokumentasi merupakan sumber data yang digunakan untuk melengkapi penelitian, baik berupa sumber tertulis, film, gambar (foto) dan karya-karya monumental yang semua itu memberikan informasi bagi proses penelitian.

\section{c. Metode Analisi Data}

Analisis data dalam penelitian ini adalah deskriptif kualitatif yang pada setiap analisis permasalahan yang ada yaitu dengan menjelaskan atau menggunakan rincian penjelasan-penjelasan yang diperoleh dari responden dan narasumber.

\section{HASIL DAN PEMBAHASAN}

\section{A. Pengelolaan Toilet Umum di Daya Tarik Wisata Kuta Lombok}

Toilet adalah fasilitas sanitasi untuk tempat buang air besar dan kecil, tempat cuci tangan dan muka. Sedangkan toilet umum adalah fasilitas sanitasi yang mengakomodasi kebutuhan membuang hajat yang digunakan oleh masyarakat umum, tanpa membedakan usia maupun jenis kelamin dari pengguna tersebut. Peraturan terkait toilet tercantum dalam Peraturan tentang toilet umum di indonesia telah di atur dalam Keputusan Menteri Kesehatan RI No.261/MENKES/SK/II/1998, dan Peraturan Pemerintah Republik Indonesia No.36 pasal 61 ayat 1 Tahun 2005. Namun dalam peraturan tersebut belum di atur secara lebih terperinci mengenai standar toilet umum. Berikut standar toilet umum yang diteapkan oleh
Kementerian Pekerjaan Umum dan Perumahan Rakyat (2016).

\section{Persyaratan Ruang}

a. Ruang untuk buang air besar (WC) : P $=80-90 \mathrm{~cm}, \mathrm{~L}=150-160 \mathrm{~cm}, \mathrm{~T}=220$ $240 \mathrm{~cm}$.

b. Ruang untuk buang air kecil (Urinoir) : $\mathrm{L}=70-80 \mathrm{~cm}, \mathrm{~T}=40-45 \mathrm{~cm}$.

\section{Sirkulasi Udara.}

Mempunyai kelembaban 40 - $50 \%$, dengan taraf pergantian udara yang baik yaitu mencapai angka 15 air-change per jam (dengan suhu normal toilet 20-27 derajat celcius).

\section{Pencahayaan.}

Sistem pencahayaan toilet umum dapat menggunakan pencahayaan alami dan pencahayaan buatan. Iluminasi standar 100 200 lux.

\section{Konstruksi Bangunan}

a. Lantai, kemiringan minimum lantai $1 \%$ dari panjang atau lebar lantai.

b. Dinding, ubin keramik yang dipasang sebagai pelapis dinding, gypsum tahan air atau bata dengan lapisan tahan air.

c. Langit-langit, terbuat dari lembaran yang cukup kaku dan rangka yang kuat sehingga memudahkan perawatan dan tidak kotor.

Bagi orang-orang yang sudah berkunjung ke tempat-tempat wisata pasti menyadari permasalahan tentang toilet umum yang ada di tempat wisata. Permasalahan tersebut tidak lain dan tidak bukan adalah tentang kebersihan toilet umum atau lebih dikenal dengan sebutan "hygiene dan sanitasi public toilet"

Toilet umum di tempat wisata juga di katakan penting karena fasilitas ini akan menunjukan kepribadian atau jati diri bangsa maupun masyarakat sekitar. Sebagai contoh: wisatawan yang berkunjung akan menilai masyarakat sekitar dari kebersihan toilet 
umum, hal ini karena setiap wisatawan akan berpikir bahwa pengelola wisata dalam hal ini adalah masyarakat sekitar maupun swadaya masyarakat telah gagal dalam menciptakan toilet umum yang bersih. Burukya, jika wisatawan tersebut adalah wisatawan asing, alangkah malunya suatu daerah atau bangsa jika memiliki toilet yang tidak dikelola dengan baik, karena wisatawan asing pastinya akan membuat hal tersebut menjadi pengalaman buruk yang akan mereka ceritakan di negara mereka.

Pengelolaan toilet umum di objek wisata khususnya di daya tarik wisata kuta lombok tengah masih tergolong sangat rendah. Kesadaran dari pengelola daya tarik wisata, dan masyarakat sebagai pengguna akan pentingnya toilet umum atas sangat rendah. Kebersihan suatu toilet umum di daya tarik wisata sangat bergantung dari pengelola atau pemerintah, pengguna, dan masyarakat sekitar. Berikut contoh beberpa toilet umum di daerah wisata yang pengelolaannya masih kurang di perhatikan.

\section{Gambar 1. Fasilitas Toilet Umum di Daya} Tarik Wisata Kuta Lombok Tengah

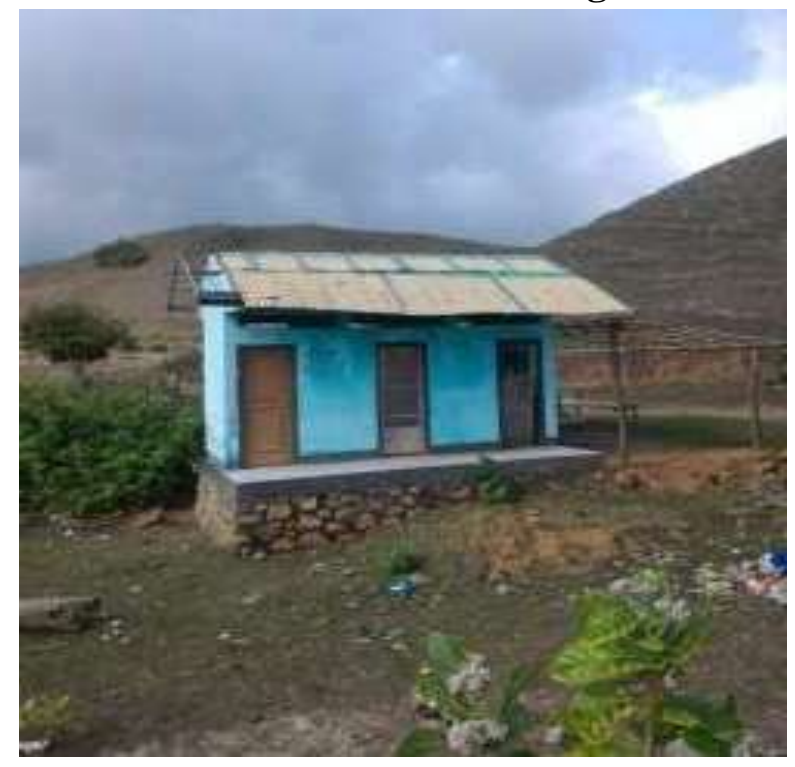

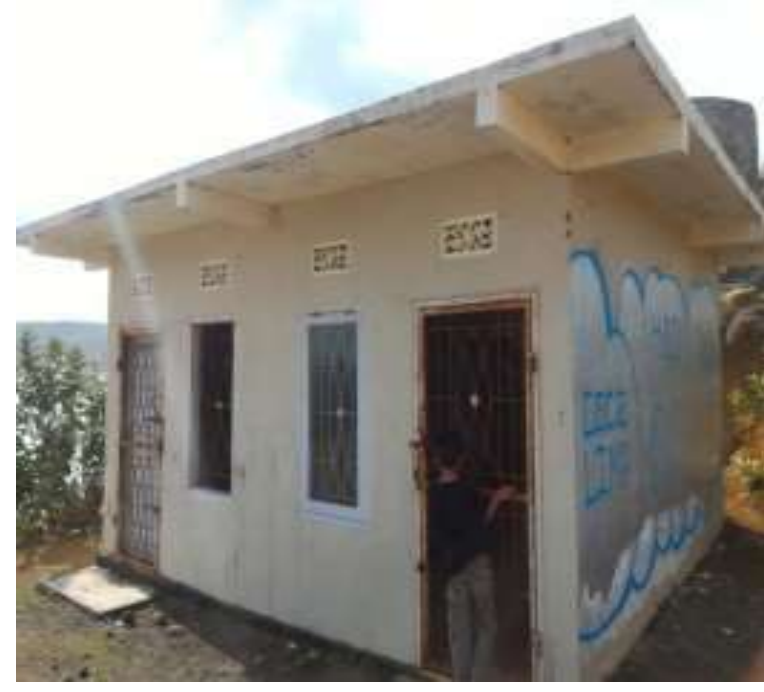

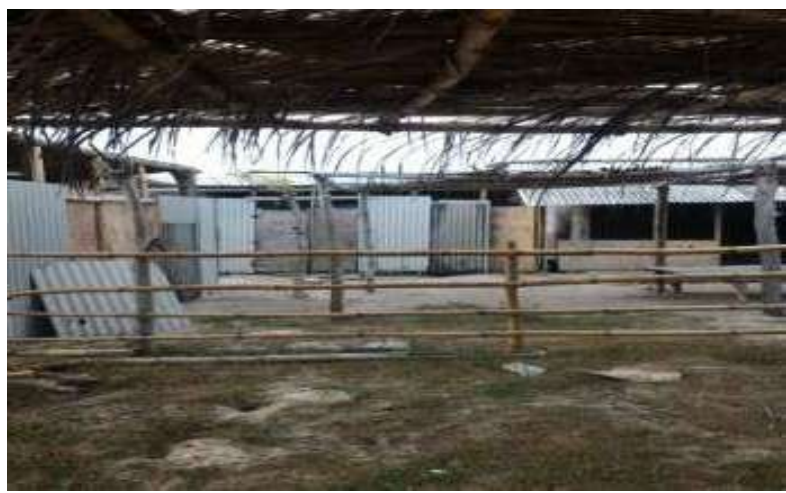

Gambar di atas adalah sebagian kecil dari banyaknya toilet umum di daya tarik wisata kuta lombok yang masih masih di kelola dengan kurang baik. Hampir semua toilet umum yang ada di tempat wisata umumnya tidak ada yang gratis, tarif yang di bebankan kepada pengguna bervariasi, tergantung dari pengelola toilet umum itu sendiri, mulai dari Rp. 2000 sampai Rp. 5000.

Berdasarkan hasil wawancara penulis dengan Bapak Tarum mengemukakan bahwa ada beberapa alasan kenapa pengelolaan toilet umum di daya tarik wisata kuta lombok tengah kurang baik yaitu:

a. Keterbasan dana untuk membangun toilet umum.

b. Kurangnya pengetahuan masyarakat untuk mengelola toilet umum.

c. Sulitnya membangun toilet umum karna kendala jauhnya tempat wisata dari 
infrastruktur jalan raya untuk membawa alat dan bahan pembangunan toilet umum.

d. Mahalnya harga pembangunan dan perawatan toilet umum.

e. Kurangnnya kesadaran pengguna toilet umum untuk menggunakannya sebagaimana mestinya.

f. Kurangnya sosialisasi tentang pengetahuan pentingnya kebersihan toilet umum.

g. Perhatian pemerintah dalam membantu menfasilitasi toilet umum masih belum maksimal.

h. Tidak tersedianya atau kurangnnya air besrsih

i. Mahalnya harga lahan untuk membangun toilet umum

Dari pengelolaan toilet tersebut memberikan dampak langsung terhadap citra pariwisata di daya tarik wisata Kuta Lombok Tengah. Dampak lain yang dirasakan langsung yaitu dapat mengurangi kepuasan wisatawan terhadap toilet umum yang disediakan oleh pengelola daya tarik wisata kuta lombok tengah. Ini terbukti dari hasil wawancara dengan salah satu wisatawan yang berkunjung di kuta lombok mengatakan bahwa "heran terhadap pengelolaan toilet umum ini, padahal tetap membayar ketika menggunakannya. Tetapi kemana uang dari hasil pembayaran tersebut. Sebaiknya uang tersebut digunakan untuk mengelola toilet umum agar lebih baik".

Berdasarkan hasil data-data diatas bahwa pengelolaan toilet umum di daya tarik wisata kuta lombok tengah belum berjalan dengan baik dan belum memenuhi standar toilet umum yang telah ditetapkan.

\section{B. Manajemen Pengelolaan Toilet Umum di Daya Tarik Wisata Kuta Lombok}

Toilet umum yang telah disediakan tidak akan dapat berfungsi dengan baik bila tidak didukung dengan pemeliharaan yang berkesinambungan. Beberapa alternatif manajemen pengelolaan yang dapat dipilih adalah sebagai berikut:

1. Didirikannya perusahaan milik daerah yang khusus mengelola toilet umum. Perusahaan ini akan mengelola toilet berdasarkan profit yang mereka peroleh dari biaya yang dipungut dari pengguna toilet. Di Cina, sistem ini direkomendasikan dengan menggabungkan tawaran pengelolaan toilet dan sampah sekaligus untuk memperoleh keuntungan bagi pengelola yang lebih besar.

2. Toilet umum dikontrakkan ke pada pengelola perorangan, pengusaha kecil maupun LSM. Dalam hal ini pihak pengelola membayar sejumlah uang kontrak kerjasama kepada pemerintah setiap tahunnya, dan kelebihan pemasukan bersih merupakan keuntungan yang diperoleh pengelola. Alternatif lain, pemasukan bersih dibagidengan sistem bagi hasil antara pengelola dan pemerintah daerah.

3. Pemerintah daerah menganggarkan dari pendapatan pajak industri pariwisata untuk biaya pemeliharaan toilet. Sistem ini sangat diperlukan untuk tempattempat denganjumlah kunjungan sedikit yang berarti tidak memperoleh keuntungan yang cukup untuk memelihara toilet sepanjang tahun.

4. Pemerintah daerah dan masyarakat setempat bermusyawarah untuk menentukan bentuk kerjasama dalam hal pengelolaan toilet umum. Hasil kesepakatan ini akan mengurangi resiko pengerusakan fasilitas toilet oleh masyarakat, karena masyarakatikut dilibatkan dalam pengambilan keputusan yang membangun rasa memiliki fasilitas tersebut oleh masyarakat.

Jika toilet umum akan dikelola bukan oleh pemerintah atau bekerjasama dengan masyarakat maupun pihak swasta, secara garis 
besarnya terdapat tiga hal penting untuk menentukan sistem manajemen pengelolaan toilet umum di tempat umum, yaitu: menguntungkan, berkesinambungan dan diterima oleh masyarakat setempat. Sistem pengelolaan yang dipilih sebaiknya memang menguntungkan bagi pihak pengelola yang merupakan daya tarik utama bagi pengelola untuk mau mengelola toilet. Dan sistem pengelolaan yang dipilih juga dapat menjamin bahwa terdapat sistem pengawasan yang rutin sehingga pihak pengelola akan melakukan pekerjaannya dengan serius dan berkesinambungan. Partisipasi masyarakat, dalam hal ini rasa memiliki oleh masyarakat akan sangat membantu terpeliharanya sarana toilet. Keterlibatan masyarakat untuk menentukan apakah sarana toilet umum yang dibangun pemerintah memang benar-benar diperlukan dan bukan dengan tujuan mengurangi pendapatan masyarakat dari penyewaan toilet, dengan sendirinya akan mengarahkan mind set masyarakat bahwa hygiene sarana yang disediakan adalah tujuan untamanya.

\section{PENUTUP}

\section{Kesimpulan}

Berdasarkan hasil pembahasan diatas dapat disimpulkan bahwa pengelolaan toilet umum di daya tarik wisata kuta lombok tengah belum berjalan maksimal, ini terbukti dari hasil observasi yang dilakukan bahwa kondisi toilet masih dalah keadaan yang kotor dan belum memadai serta belum memenuhi standar toilet umum yang telah ditetapkan.

Dalam pengelolaannya perlu ada kerjasama yang besinergi antara pemerintah dan masyarakat setempat agar manajemen pengelolaan toilet umum berjalan dengan baik. Masyarakat sebagai pengelola fasilitas toilet umum di harapkan mampu menjaga dan merawat fasilitas tersebut. Pengelola di wajibkan untuk menunjuk seseorang atau kelompok untuk mengontrol kebersihan toilet umum tersebut secara berkala. Pengelola juga di harapkan mampu mengelola pendapatan yang di dapat dari uang yang di bebankan kepada pengguna toilet umum tersebut.

\section{DAFTAR PUSTAKA}

[1] Peraturan Pemerintah Republik Indonesia Nomor 36 tahun 2005 tentang Bangunan Gedung”. Diakses 21 oktober 2017. Tersedia Pada eodb.ekon.go.id/download/peraturan/pp/PP _36_2005.pdf.

[2] Kementerian Pekerjaan Umum dan Perumahan Rakyat. 2016. Standar Toilet Umum Indonesia. URL: http://pustaka.pu.go.id/?Q=content/standar -toilet- umum-indonesia. Diakses tanggal 10 September 2019.

[3] Kurniansah, R. dan Hali, MS. 2018. Ketersediaan Akomodasi Pariwisata Dalam Mendukung Pariwisata Perkotaan (Urban Tourism) Sebagai Daya Tarik Wisata Kota Mataram Provinsi Nusa Tenggara Barat. Jurnal Bina Wakya. 1 (1): 39-44.

[4] Darwis, RR. Hendraningrum, A. dan Adriani, Y. 2016. Kelayakan Fasilitas Publik Dalam Kawasan Industri Wisata Belanja Di Kota Bandung: Studi Kasus Terhadap Toilet Dan Musola. Jurnal Barista. 3(2): 188-202.

[5] Rozita. Suprianto, A. Mahdani. Masyhudi, Lalu. dan Kurniansah, Rizal. 2019. Kajian Tentang Potensi Daya Tarik Wisata Syariah Di Pulau Lombok. Jurnal Media Bina Ilmiah. 13 (12): 1863-1872.

[6] Kurniansah, Rizal. Dan Rosida, Lia. 2019. Strategi Pengembangan Pariwisata Perkotaan (Urban Tourism) Kota Mataram Provinsi Nusa Tenggara Barat. Jurnia Media Bina Ilmiah. 14 (2): 2061-2068 